\title{
A LED STREET LIGHTING SYSTEM SUPPLIED BY MAINS OR BATTERY WITH AN INTEGRATED CONTROL AND MONITORING NETWORK
}

\author{
Carlos H. Barriquello, Gustavo W. Denardin, Rafael A. Pinto, \\ Priscila E. Bolzan, Alexandre Campos, Ricardo N. do Prado \\ Federal University of Santa Maria - UFSM \\ barriquello@gedre.ufsm.br
}

\begin{abstract}
This paper presents a LED street lighting system designed for applications where it is important to remove the lighting energy consumption from the mains during the Peak Load Time (PLT) or to implement a street lighting system capable of maintaining the lighting during mains fault. The proposed system consists of only one flyback converter capable to supply the LEDs by mains or by battery and a control network. A design methodology of the proposed system is presented aiming high power factor, so that the same converter can be used in the power factor correction stage. Such converter is also used to recharge the battery. The complete circuit was implemented and experimental results are shown in order to validate the design methodology, which complies with the IEC 61000-32 standard. The control network enables disconnection of the street lighting system from the mains during peak load time, reducing its impact in the distributed power system automatically at overload conditions. It also allows to reduce the power consumption, decrease the management cost and monitor the status information of each street lighting unit. In order to meet the system requirements, a wireless sensor network is employed. Field tests have been performed on IEEE 802.15.4-compliant wireless control units. The obtained experimental results show that the proposed distributed control network is able to meet the requirements of a LED street lighting system.
\end{abstract}

Keywords - Flyback Converter, LED Street Light, Peak Load Time, Control Network, IEEE 802.15.4.

\section{INTRODUCTION}

The street lighting system (SLS) of a city plays an important role on its infrastructure. It is responsible of guaranteeing the society security and living during night time, traffic safety, and city appearance. In the beginning, the control of the oil lamps was performed manually. With the invention of the electric lamps, the control of the street lighting started to be carried on automatically, by means of photocells, according to the light level. Light sources and their respective control gears are being constantly developed since their invention. On the other hand, photocells have been the adopted control system of public lighting for more than sixty years.

Modern street lighting systems demand intelligent control networks, in order to reduce the power consumption, decrease the maintenance and management cost, monitor the status information of each device (lamp status, current and voltage

Manuscript received on 26/10/2012 and revised on 19/01/2013. Second revision concluded on 14/03/2013. Accepted for publication on 05/04/2013 upon recommendation of the Editors Pedro Francisco Donoso-García and Henrique A. C. Braga. measurements, etc.) and enable new control capabilities to the system (e.g.: dimming).

The street lighting systems features a large number of independent devices, with geographic distribution depending on the city streets. Then, adding communication capabilities to these devices requires a complex network topology, as well as interoperability, scalability, security, robustness, low cost, ease to use and maintenance. A few contributions in the literature suggest some technologies that can be used to control a street lighting system. Some use the power lines for data transmission (PLC) [1], while others use wireless communication, such as cellular networks [2], wireless sensor networks [3] and both combined [4].

Main drawbacks of the PLC technology are noisy medium, high signal attenuation, susceptibility to interference from nearby devices, high cost, high complexity and poor scalability. Similarly, the scalability and reliability of cellular networks are questionable, especially under high load traffic. On the other hand, wireless sensor networks scalability is highly dependent on the routing algorithm performance. Therefore, designing a routing algorithm with high scalability and low overhead is a challenge.

Regarding the lamp types used in SLSs, the most commonly used are the high pressure discharge lamps, e.g.: mercury vapor lamps, high-pressure sodium (HPS) lamps, and metal halide (MH) lamps. The discharge lamps demand a control gear that provides their starting and steady state behavior, which is commonly an electromagnetic ballast [5],[6].

Light emitting diodes (LEDs) are being presented as an alternative to replace the conventional lighting systems. Despite of their widespread use as signalling systems, LEDs are not commonly used as lighting systems. However, recent technology is improving gradually the LEDs efficiency and color quality, which allows their application in lighting systems [7]. The use of LEDs in street lighting systems started to be reported in the last few years, and it is being considered a very good solution to replace the conventional HID-based lighting systems, because of the longer lifetime, higher luminous efficiency in mesopic visual conditions, and higher color rendering index (CRI) [8].

The artificial lighting consumes a considerable amount of electricity generated in the world. So, with the concern about the increase of energy consumption in various segments, the development of more efficient lighting systems is really important.

Another problem faced by utilities is the peak load time, which is a short period of the day where the energy consumption is maximal. Due to this characteristic, the power generation plants and transmission lines must be able to supply the highest power to meet the demand. However, at off-peak 
periods, the system works with reduced power. A typical demand curve can be found in [9], where is shown that the PLT occurs daily between 6 p.m. and 9 p.m.

The street lighting is not only relevant for the visual appearance of the city, but it also provides better traffic view, safety to citizens, leisure activities, trade and culture overnight. However, street lighting is also responsible for overloading the electrical system during the PLT. This is the period of the day in which the highest demand of energy takes place and the city lights are usually turned on at the same time, loading the electrical system even further [10].

Thus, an alternative to reduce the power consumption from the mains during PLT, and also to ensure lighting in the absence of electricity from the mains is to provide energy for the street lighting system through an alternative source of energy, such as battery [11],[12]. Thus, the overload can be reduced during the PLT. The battery can be charged when the demand is lower, usually between 11 p.m. and 6 a.m [9].

For this application, LEDs have become attractive because they are supplied by DC current, and do not require a high voltage pulse for ignition, different from the discharge lamps. These features render LEDs as an ideal light source to be supplied from batteries. Besides, they have high luminous efficacy and long useful life, which contribute to reducing the maintenance costs of the SLS [8],[10],[12],[13].

Therefore, this work presents a single-stage flyback converter for SLS applications based on LEDs that is able to remove the energy consumption from the mains during the PLT and can still be used as an emergency lighting system. The most relevant contribution of the proposed circuit is to supply the LEDs from the mains with high power factor or from the battery, and also to charge this battery employing only one converter. The battery is connected in series with LEDs being recharged with the same current, simplifying the control circuit.

Additionally, it is proposed a distributed control network to manage the LED-based street lighting system. Such network enables real-time management of the street lighting system, making possible to monitor the status of the LED array, battery and power circuitry; send control messages to a device, individually, or to a group of devices; keep local clocks synchronized; and so on.

This paper is organized as follows: Section II presents an outline of the proposed street lighting system. In section III, the power circuitry for the LED driver capable to supply the LEDs by mains or by battery and its design methodology is presented. In Section IV, the proposed control network to be used in the SLS is depicted. The experimental results of the proposed street lighting system are presented in Section V. Finally, the paper is concluded in Section VI.

\section{PROPOSED STREET LIGHTING SYSTEM}

Some street lighting systems using LEDs have been developed and can be found in [8]. These systems usually use converters that are well known in literature and sometimes used in electronic ballast for discharge lamps. More recent SLS based on LEDs have applied integrated topologies composed by buck, boost, buck-boost, and flyback converters
[7],[12]. Such approaches intend to achieve high power factor, high efficiency, and regulate the LEDs current to control the light output [13].

The proposed street lighting system based on LEDs provides high power factor, high operating efficiency, and regulates the output current to control the light. The power stages of the proposed circuit for a street lighting system is composed of a Power Factor Correction (PFC) stage, a DCto-DC power stage (driver) used to control the LEDs current when supplied by mains or by battery, and a bi-directional converter to charge the battery.

Moreover, we propose the integration of a control network with communication capability to the street lighting system. The use of such a control network is justified because the system is expected to be frequently connected and disconnected from the mains, resulting in a variable power requirement. Therefore, it is important to have a way to measure the power and energy consumption in a perlamp basis, in order to keep track of the system efficiency according to its cycles of operation. Indeed, a communication network can be of great assistance to achieve system-wide synchronization. This feature is required by the system in order to know the peak load time occurrences, given that those events can vary according to several factors, such as the weather, the seasons, the holidays and so on.

Further, the failure of one or more LEDs can be detected due to abrupt changes in the converter output voltage. If the system is connected to a network, the circuitry can be monitored and the luminaire can be quickly replaced. In the same way, the battery can be monitored, which allows reporting the occurrence of any problem as well as the estimated battery life span. Thus, not only a preventive maintenance of the system can be easily programmed, but also software updates can be done (enabling enhancements and addition of new functions).

The complete proposed street lighting unit is shown in Figure 1, consisting of a power circuitry and a network control module. The overall system is described in the next sections. We first present the power circuitry design. Then, the proposed control network and the results of field tests are presented.

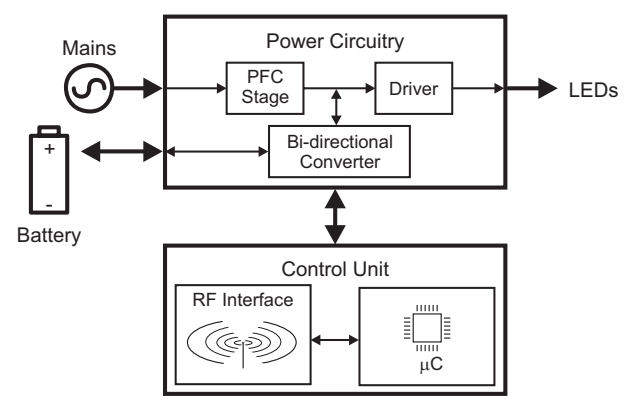

Fig. 1. Block diagram of the proposed street lighting system unit, with power circuitry and control network module.

\section{POWER CIRCUITRY}

The LED lamp is composed by 30 Luxeon Rebel LEDs (LXML-PWN1-0100) connected in series. The luminaire voltage is $102 \mathrm{~V}_{\mathrm{DC}}$ and its nominal current is $700 \mathrm{~mA}$. 


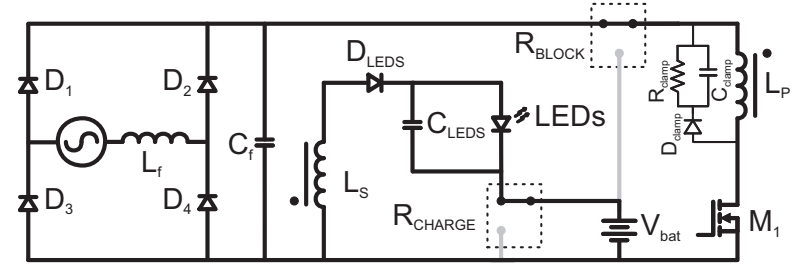

(a) Proposed topology with the relays $R_{B L O C K}$ and $R_{\text {CHARGE }}$ on the first position (normally closed state). The LEDs and the batteries are supplied by mains.

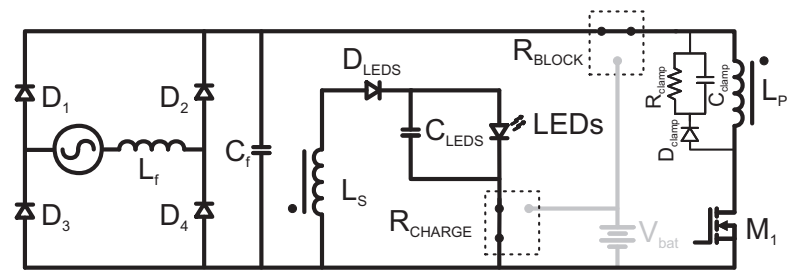

(b) Proposed topology with the relay $\mathrm{R}_{\text {CHARGE }}$ on the second position. In this operation mode only the LEDs are supplied by mains.

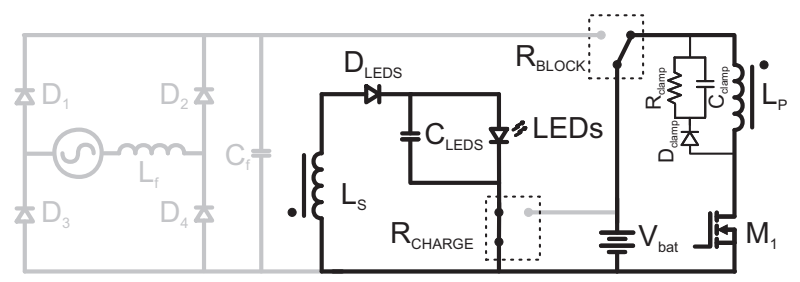

(c) Proposed topology with both relays on the second position. In this operation mode only the LEDs are supplied by the batteries.

Fig. 2. Proposed power circuitry topology.

The battery bank used was specified following the design methodology proposed by [9]. Thus, four 19 Ah (NEWMAX FNC 12190-C [14]) batteries connected in series are used, resulting in a battery bank voltage of $48 \mathrm{~V}$.

The proposed topology must work as a step-down converter when the LEDs are supplied by mains and as a step-up converter when the battery supplies the LEDs. In this work, a single flyback converter is employed to meet these requirements.

Among the modulation techniques used to supply LEDs, the direct current is the one that provides the highest luminous efficiency [15]. If the current level for charging the batteries is designed to have the same value as that used to supply the LEDs, the battery bank can be connected in series with these devices. In this way, the same converter used to supply the LEDs from the mains can be employed to charge the batteries. This method reduces the number of components and simplifies the control circuit. The proposed circuit is shown in Figure 2.

In this circuit, the relay $\mathrm{R}_{\text {Block }}$ (SPDT - Single Pole Double Throw) determines the power supply to the converter (mains or batteries). The relay $\mathrm{R}_{\text {Charge }}$ (SPDT) connects the LEDs in series with the batteries so that it can be recharged. The Figure 2(a) shows the proposed topology supplying the LEDs, and charging the batteries by mains. In this operation mode, the relays are on normally closed state. Thus, when the switch $\mathrm{M}_{1}$ is turned on, the mains voltage is applied on the flyback primary winding $\left(\mathrm{L}_{\mathrm{P}}\right)$. The diode $\mathrm{D}_{\mathrm{LEDs}}$ is reversed biased, and the capacitor $\mathrm{C}_{\mathrm{LEDs}}$ maintains the current in the LEDs.
When the switch $\mathrm{M}_{1}$ is turned off, the energy stored in the flyback inductor is transferred to the output capacitor $\left(\mathrm{C}_{\mathrm{LEDs}}\right)$ and to the LEDs, as well as to the battery connected in series with the LEDs. The battery is disconnected from the circuit when it is fully charged by $R_{\text {CHARGE }}$. As shown in Figure 2(b), only the LEDs are supplied by mains in this operation mode.

When a mains failure occurs or during the PLT, the LEDs are supplied by the batteries, as shown in Figure 2(c). At this time, the relay $\mathrm{R}_{\text {CHARGE }}$ should keep only the LEDs connected to the flyback converter output, while the relay $\mathrm{R}_{\mathrm{BLOCK}}$ should switch to connect the primary winding to the batteries.

The gate drive is performed by a microcontroller that is also used to control the output current, and to switch the relays according to the PLT. The LEDs current is sensed by an integrated Hall IC and regulated by a proportional-integral (PI) controller digitally implemented. The relays operate under zero current switching (ZCS) in order to increase their useful life $\left(10^{7}\right.$ operations). Then, the expected useful life of the relays does not endanger the proposed lighting system.

The battery is used to supply the system every day during the PLT. For this reason, there is not enough time for a selfdischarge and, its recharge method does not require a floating voltage. Therefore, the battery can be easily disconnected from the circuit when it reaches its nominal voltage.

\section{A. Design Methodology}

The Power Factor Correction (PFC) stage is usually performed by a DC-to-DC converter operating in discontinuous conduction mode (DCM). However, with the proper design of the flyback converter it is possible to achieve high power factor and low total harmonic distortion (THD) of the input current when it is supplied by mains.

The proposed converter is designed to operate with input voltage of $48 \mathrm{~V}_{\mathrm{DC}}$ when supplied from the batteries, and 220 $\mathrm{V}_{\mathrm{AC}}(60 \mathrm{~Hz})$ when supplied from the mains. Similarly, the converter output voltage can change from $102 \mathrm{~V}_{\mathrm{DC}}$, when only the LEDs are supplied either from the mains or from the battery, to $150 \mathrm{~V}_{\mathrm{DC}}$ when the battery is recharged connected in series with the LEDs.

The symbols, their meanings and the values calculated or used to evaluate the equations in the design of the converter are all summarized in Table I.

\section{1) Battery Bank Specification}

According to the battery bank design methodology presented in [9], four 19 Ah (FNC 12190-C) batteries are sufficient to ensure the operation of the proposed system for three hours, and the required recharging time is 7.5 hours.

\section{2) Flyback Converter Supplied by the Batteries}

The flyback converter inductances are designed in order to optimize the circuit operation when supplied by the batteries. Then, the primary winding inductance is calculated by (1), and the secondary winding inductance by (2).

$$
\begin{gathered}
L_{p}=\frac{\left(V_{\text {in_min }}\right)^{2}\left(D_{\text {bat_max }}\right)^{2} \eta}{2\left(V_{o} I_{o}\right) f_{s}} \\
L_{s}=L_{p} \times\left[\frac{\left.V_{o}\left(1-D_{b a t \_m a x}\right)\right)}{\left(V_{\text {in_min }}\right) D_{\text {bat_max }}}\right]^{2}
\end{gathered}
$$


TABLE I

Symbols and values used in the converter design

\begin{tabular}{ccc}
\hline Symbol & Meaning & Value \\
\hline$\eta$ & Estimated efficiency & $90 \%$ \\
\hline$V_{\text {in_min }}$ & Minimum input voltage of the converter & $41 \mathrm{~V}$ \\
\hline$D_{\text {bat_max }}$ & Maximum duty-cycle & 0.7 \\
\hline$V_{o}$ & Output voltage & $102 \mathrm{~V}$ \\
\hline$I_{o}$ & Output current & $700 \mathrm{~mA}$ \\
\hline$f_{s}$ & Switching frequency & $60 \mathrm{kHz}$ \\
\hline$L_{p}$ & Primary winding inductance & $86 \mu \mathrm{H}$ \\
\hline$L_{s}$ & Secondary winding inductance & $97 \mu \mathrm{H}$ \\
\hline$D_{\text {mains }}$ & Duty cycle for the circuit supplied by mains & 0.16 \\
\hline$D_{\text {mains_max }}$ & Maximum value for the duty cycle & 0.318 \\
\hline$V_{\text {in_pk }}$ & Line voltage peak value & $311 \mathrm{~V}$ \\
\hline$C_{L E D s}$ & Output capacitor & $470 \mu \mathrm{F}$ \\
\hline$R_{d}$ & Dynamic resistance of LEDs & $13.95 \Omega$ \\
\hline$I_{L E D s}$ & Output current ripple & $20 \%$ \\
\hline$f_{\text {mains }}$ & Mains frequency & $60 \mathrm{~Hz}$ \\
\hline$V_{\text {ds_max }}$ & Maximum voltage on the switch & $450 \mathrm{~V}$ \\
\hline$I_{d s_{-} r m s}$ & Maximum RMS current on the switch & $2.7 \mathrm{~A}$ \\
\hline$R_{\text {clamp }}$ & Resistance of the clamp network & $10 \mathrm{k} \Omega$ \\
\hline$C_{\text {clamp }}$ & Capacitance of the clamp network & $22 \mathrm{nF}$ \\
\hline$L_{f}$ & Inductance of the input filter & $1.022 \mathrm{mH}$ \\
\hline$C_{f}$ & Capacitance of the input filter & $680 \mathrm{nF}$ \\
\hline
\end{tabular}

\section{3) Flyback Converter Supplied by Mains}

The flyback inductor has been designed for the circuit supplied by the batteries and cannot be changed with the circuit under operation. However, the input voltage when the converter is supplied by mains has a peak voltage $\left(V_{i n_{-} p k}\right)$ of $311 \mathrm{~V}$. Besides, the output voltage $\left(V_{o}\right)$ is $150 \mathrm{~V}$ because the battery is connected in series with the LEDs. For this reason, the duty cycle or the switch frequency must be changed in order to maintain the output power at the desired value. The duty cycle during this mode of operation $\left(D_{\text {mains }}\right)$ can be obtained by (3).

$$
D_{\text {mains }}=\sqrt{\frac{4 L_{p}\left(V_{o} I_{o}\right) f_{s}}{\left(V_{\text {in_p }}\right)^{2} \eta}}
$$

The flyback converter operates in DCM when it is supplied by mains. Thus, if the duty cycle is held constant, the input current follows the input voltage and its waveform is sinusoidal. The power factor is high and the THD is low. However, the conduction mode depends on the relationship between the inductances $L_{p}$ and $L_{s}$, which sets a maximum value for the duty cycle $\left(D_{\text {mains_max }}\right)$. Thus, the duty cycle obtained by (3) should be less than the maximum duty cycle calculated by (4) to ensure DCM.

$$
D_{\text {mains_max }}=\frac{\sqrt{L_{p}}\left(V_{o}\right)}{\sqrt{L_{s}}\left(V_{i n \_p k}\right)+\sqrt{L_{p}}\left(V_{o}\right)}
$$

If the duty cycle $D_{\text {mains }}$ is higher than $D_{\text {mains_max }}$, the switching frequency should be modified so that the converter operates in DCM and provides the necessary output power. In such case, the switching frequency can be calculated by (5).

$$
f_{s \_ \text {mains }}=\frac{\left(V_{\text {in_pk }}\right)^{2}\left(D_{\text {mains_max }}\right)^{2} \eta}{4 L_{p}\left(V_{o} I_{o}\right)}
$$

When the battery is fully charged, the flyback converter load is only the LEDs. Thus, the duty cycle must be decreased to 0.131 in order to maintain the output voltage $\left(V_{o}\right)$ at $102 \mathrm{~V}$. The duty cycle value was calculated by (3).
The core of the flyback transformer is calculated considering all operation modes. The core specification for the circuit supplied from the mains resulted in a NEE 30-15-14. However, the worst case (largest size) occurs when the battery supplies the LEDs, requiring the core NEE 40-17-12, which was used in the prototype. Nevertheless, considering that only one core is used by the circuit to supply the LEDs by the mains or by battery, and to recharge the battery bank through the mains, this small increase in the size of the transformer does not affect significantly the size of the topology.

\section{4) Output Capacitor Design}

The output capacitor of a converter is generally designed for limiting the voltage ripple on the load. However, for the LEDs is important to limit the current ripple. The LED model can be represented in a simplified form by three elements connected in series: an ideal diode, a constant voltage source, and its dynamic resistance. Therefore, the low value of the dynamic resistance is the responsible for the current ripple in the LED. Thus, the output current ripple is obtained by dividing the voltage ripple by the dynamic resistance of the LED. The output capacitor $\left(C_{L E D s}\right)$ is designed to limit the output current ripple considering the rectified input voltage ripple, and can be obtained by (6).

$$
C_{L E D s}=\frac{D_{\text {mains }}}{2 \times R_{d} \times \Delta I_{L E D s} \times f_{\text {mains }}}
$$

\section{5) Switch Specification}

This topology is composed by one shared switch, which must be designed for both operation modes. Thus, the maximum voltage on the switch can be calculated from (7). The maximum value occurs when the circuit is supplied by mains, and the batteries are being recharged in series with the LEDs.

$$
V_{d s \_ \text {max }}=V_{\text {in_pk }}+V_{o} \sqrt{\frac{L_{p}}{L_{s}}}
$$

On the other hand, the maximum current on the switch occurs when the flyback converter is supplied by the batteries. Thus, the RMS current value is obtained by (8). In this work, the CoolMOS SPW20N60 is used due to its low drain-source on-state resistance $(190 \mathrm{~m} \Omega)$.

$$
I_{d s \_r m s}=\frac{2\left(V_{o} I_{o}\right)}{D_{\text {bat_max }}\left(V_{\text {in_min }}\right) \eta} \sqrt{\frac{D_{b a t \_m a x}}{3}}
$$

\section{CONTROL AND MONITORING NETWORK}

The street lighting system features a large number of independent devices, with geographic distribution depending on the city streets. Clearly, each device of this system must be able to communicate at least with a utility control center in order to receive control commands, send status and metering information as well to maintain its local clock synchronized. Note that such system is similar to an automatic meter reading (AMR) system, which is one of the main components of a Smart Grid [16]. Recently, AMR technology has evolved to a wireless AMR, which employs two-way radios between utilities and the metering devices. There are several wireless 
technologies that can be used to provide the required network infrastructure, such as cellular networks and short range radio [17]. Among those, wireless sensor networks (WSN) based on short range radio have been widely recognized as a promising technology that can enable WAMR systems [18].

Wireless sensor networks presents a collaborative operation that brings significant advantages over traditional communication technologies, including rapid deployment, low cost, flexibility, and aggregated intelligence via parallel processing [18]. Its recent advances have made feasible to deploy Smart Utility Networks (SUN). SUNs are intended to enhance the public utilities services, such as: monitoring and controlling the electricity, water and gas supply [19].

The network model adopted by most of the wireless sensor networks is based on the OSI reference model. Usually, in this model, only the physical, data link, network and application layers are implemented. The IEEE 802.15.4 ${ }^{\mathrm{TM}}$ standard is commonly employed to perform the physical and data link layers for WSNs. While other wireless network standards aim to achieve large throughput and high quality of service, the IEEE $802.15 .4^{\mathrm{TM}}$ is designed to provide simple wireless communications with relatively short range, low power, limited data throughput, low cost, and small size. Despite of these features, such standard is sufficient to satisfy the requirements of most remote monitoring system [20]. Although the IEEE $802.15 .4^{\mathrm{TM}}$ is a well-established standard, it does not include network and application layers, which should be properly specified.

Therefore, a possible approach to a network layer is proposed in the next subsection, which is applied into the control network for the LED street lighting system. For the sake of simplicity and convenience, a single unit of the proposed lighting system will be called node or router.

\section{A. Geographic routing}

Currently, WSN physical and data link layers are based on well-established standards. Nevertheless, network formation and multi-hop routing is still a challenging problem. A variety of protocols were developed in order to properly perform these routing tasks. However, those existing protocols may not satisfy the requirements for large-scale applications [21]. Geographic routing approach is one of the most suitable routing strategies for such scenario, due to its low overhead and high scalability features [22]-[24].

Geographic routing mainly relies on a really simple geographic greedy-forwarding strategy, where each router node must select a locally optimal neighbor with a positive progress towards the data packet destination [25]. In this strategy, the destination address is the position of the destination node, instead of a topological address. A node position could be obtained by preconfiguration if the node is stationary, or by a GPS receiver. As network nodes are static in the street lighting case, the location information of the nodes is stored during the installation process.

When considering realistic outdoor scenarios, such as a city, any block could turn into a void. A void occurs when all neighbors of a router node are farther away from the destination node than the router itself. In this case, the router fails to locate a next hop node through greedy strategy. If only the greedy-forwarding algorithm is used, packets have to be discarded when a void is reached. However, a void does not necessarily mean that there is no route to the destination, because if the network is connected, a valid topological path exists by circumventing the void.

Many researchers argue that a dense deployment of wireless nodes can reduce the likelihood of the void occurrence in the network [23],[25],[26]. Indeed, in scenarios without obstacles that can be true. However, in outdoor large scale wireless networks it is unlikely to have such scenarios. Void handling techniques is an important issue to be addressed in such networks. Although there are several solutions, most of them present some limitations, such as: low effectiveness of handling voids (no guarantee of delivery), high resource occupancy, long detours of stuck packets, not optimal path discovery and high complexity. Moreover, most of voidhandling techniques are designed with some unrealistic assumptions [25]. Among these we can mention equal node transmission range, symmetric links, reliable nodes, unrealistic scenarios, unidirectional information flow and so on. Thus, these techniques do not consider the impact of the lower network layer in the performance of the routing algorithms.

In order to overcome the above mentioned challenges, we developed a hybrid geographic routing strategy using a heuristic approach with distinguished enhancement considering performance criteria, such as, hop count, optimal path selection, message overhead, scalability and adaptability to sparse networks (which is the case of a street lighting system). We have described the complete routing algorithm in a previous work [27].

\section{EXPERIMENTAL RESULTS}

The experimental results are organized in three sections. At first, the results of the flyback converter supplied by mains are presented, followed by the results of the same flyback supplied by the batteries. Finally, the obtained results for the control module responsible for the network and the results for the network itself are presented.

\section{A. Flyback Converter Supplied by Mains}

Figure 3 shows the mains voltage and current waveforms for the circuit supplying the LEDs and charging the battery. The input current waveform is sinusoidal, resulting in a high power factor (0.999). The nominal input voltage is $220 \mathrm{~V}$ (RMS) and the current value (RMS) is $518 \mathrm{~mA}$. Thus, the input power is $112 \mathrm{~W}$. Figure 4 shows the output voltage and current waveforms of the converter, which is composed by the LEDs and the batteries connected in series. The average output voltage is $145 \mathrm{~V}$, and the nominal current is $718 \mathrm{~mA}$. The output power is $105 \mathrm{~W}$. Then, the efficiency of the topology in this case is approximately $93 \%$.

High values of efficiency can be obtained from a singlestage converter. However, if the voltage spike on the switch is high, the switching loss can be higher, decreasing the converter efficiency. The voltage spikes occurring on the switch due to leakage inductance present in the flyback transformer associated with the intrinsic capacitance of the MOSFET and 


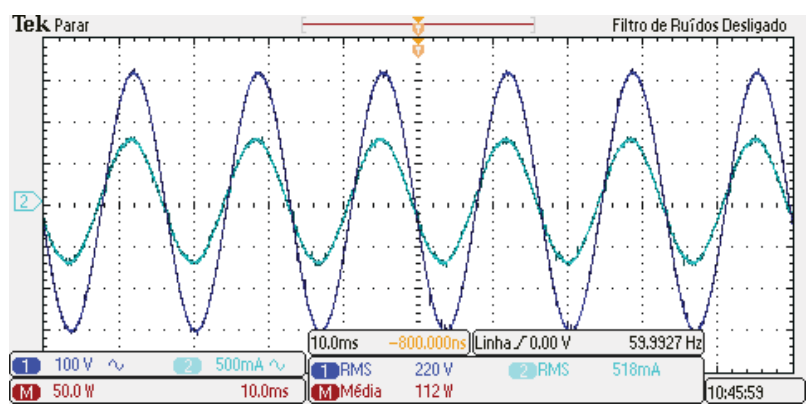

Fig. 3. Input voltage and current waveforms for the proposed circuit supplying the LEDs and charging the battery (100 V/div, $500 \mathrm{~mA} / \mathrm{div}$, $10 \mathrm{~ms} / \mathrm{div})$.

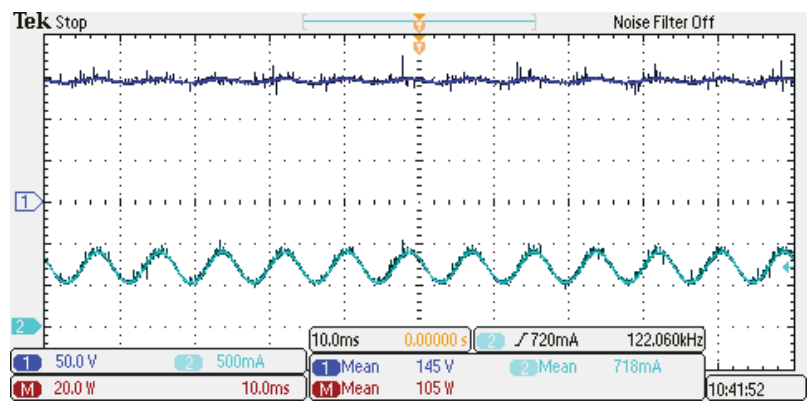

Fig. 4. Output voltage $\left(\mathrm{V}_{\mathrm{LEDs}}+\mathrm{Vbat}\right)$ and current $\left(\mathrm{I}_{\mathrm{LEDs}}=\mathrm{Ibat}\right)$ waveforms (50 V/div, $500 \mathrm{~mA} / \mathrm{div}, 10 \mathrm{~ms} / \mathrm{div})$.

other parasitic capacitances of the circuit. In this work, an RCD clamp circuit was used to limit the peak voltage on the drain of the MOSFET. Besides, the flyback transformer has a turn ratio of approximately $1: 1$, which contributes to the manufacture of the transformer in order to reduce the leakage inductance and hence reduce the peak voltage in the switch. Thus, a MOSFET with less breakdown voltage and low onstate resistance can be employed, reducing the conduction and switching losses.

The peak current in the switch is approximately $9.8 \mathrm{~A}$, and its RMS value considering the low frequency ripple is $1.56 \mathrm{~A}$. The high level of the switch voltage is $440 \mathrm{~V}$, and the peak voltage reaches $550 \mathrm{~V}$ due to the leakage inductance of the flyback inductor used.

General lighting applications have to meet IEC 61000-3-2 Class $\mathrm{C}$ regulations for input current harmonics. Then, Table II shows the values of the harmonic spectrum of input current for the proposed circuit, which complies with the standard. The total harmonic distortion (THD) is $3.8 \%$.

Figure 5 shows the input voltage and current waveform when the batteries are fully charged, and the load is composed only by the LEDs. In this operation mode, the input current is $322 \mathrm{~mA}$, and the input power is $69 \mathrm{~W}$. The voltage and current waveforms in the LEDs are shown in Figure 6. The average output voltage is $91.4 \mathrm{~V}$, and the average output current is maintained at $711 \mathrm{~mA}$. Therefore, the output power is $65.2 \mathrm{~W}$. The efficiency is $94.5 \%$, the THD of the input current is $6 \%$ and the power factor is 0.998 . The peak current on the switch is $7.9 \mathrm{~A}$, and the RMS value is $1.13 \mathrm{~A}$. The peak voltage on the switch is less than $450 \mathrm{~V}$.

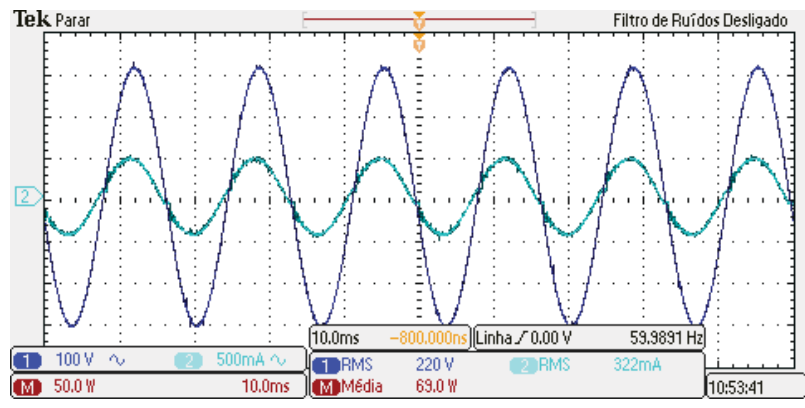

Fig. 5. Input voltage and current waveforms for the proposed circuit supplying only the LEDs (100 V/div, $500 \mathrm{~mA} / \mathrm{div}, 10 \mathrm{~ms} / \mathrm{div})$.

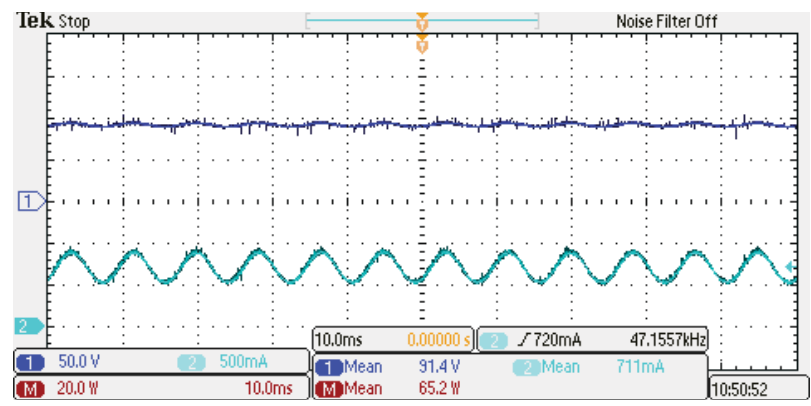

Fig. 6. Voltage and current waveforms in the LEDs (50 V/div, 500 $\mathrm{mA} / \mathrm{div}, 10 \mathrm{~ms} / \mathrm{div}$ ).

\section{B. Flyback Converter Supplied by the Batteries}

The battery bank voltage is $48.3 \mathrm{~V}$ and the average input current is $1.42 \mathrm{~A}$. The input power is $68.5 \mathrm{~W}$. In this operation mode, the battery current has a triangle waveform because it is the same of the switch. The RMS current on the switch is $2.33 \mathrm{~A}$, and the maximum voltage is $136 \mathrm{~V}$. The current on the LEDs is maintained constant at $707 \mathrm{~mA}$, and the output power is $63.1 \mathrm{~W}$. Thus, the efficiency of the circuit supplied by battery is $92.1 \%$.

\section{Control Network}

For the field tests, a control unit module was developed. It comprises a IEEE $802.15 .4^{\mathrm{TM}}$ compliant radio and a 32 bit microcontroller. The features of the main components of such module (microcontroller and radio) are presented in Table III. The control unit is responsible of managing the power converters, monitoring the status of the power circuitry and communicating over the network.

All of those functions should run concurrently. Thus, the software structure should allow the management of the shared resources and provide fault tolerance. In this context, the use of a real-time operating system (RTOS) becomes attractive. The integration of a RTOS can solve a variety of problems that can occur in the application code, since it

TABLE II

Harmonic spectrum of input current

\begin{tabular}{ccccccc}
\hline Harmonics & $\mathbf{2}$ & $\mathbf{3}$ & $\mathbf{5}$ & $\mathbf{7}$ & $\mathbf{9}$ & $\mathbf{1 1 - 3 9}$ (odd) \\
\hline Input current $(\%)$ & 0.4 & 1.2 & 1.2 & 0.7 & 0.6 & $<1$ \\
\hline IEC 61000-3-2 (\%) & 2 & 29.9 & 10 & 7 & 5 & 3 \\
\hline
\end{tabular}


TABLE III

Prototype features - radio and microcontroller

\begin{tabular}{ccc}
\hline Features & Radio Module & Microcontroller \\
\hline Supply Voltage $(\mathrm{V})$ & $2.4-3.6$ & $1.8-3.6$ \\
\hline Sleep Current $(\mu \mathrm{A})$ & 2 & 21 \\
\hline Current Consumption $(\mathrm{mA})$ & $19(\mathrm{Rx}) / 23(\mathrm{Tx})$ & 32 \\
\hline Operating Frequency $(\mathrm{GHz})$ & 2.4 & - \\
\hline CPU type @ MHz & - & 32 bit Coldfire V1 @ 25 \\
\hline Bit Rate $(\mathrm{kbps})$ & 250 & - \\
\hline Memory $(\mathrm{KB})$ & - & 8 (Data) / 128 (Program) \\
\hline
\end{tabular}

provides multitasking capability and allows the application to be broken down into smaller pieces. Therefore, the software of the prototype makes use of a RTOS, allowing independent development of each system task, while keeping them isolated. This feature helps to maintain the system in operation even if a particular task no longer operates. Furthermore, it corrects faults whenever possible, avoiding system failures. For the performed tests, a simple application layer (set of messages) was developed, which includes ON/OFF commands, dimming commands, fault alarms and synchronization messages.

Although the radio is capable of transmitting at $250 \mathrm{kbps}$, actual throughput largely depends on network overhead and system software architecture. In the obtained results, the integration of the network stack into the RTOS shown to be efficient and reliable, achieving data rates up to $230 \mathrm{kbps}$, which yields an efficiency of $92 \%$. Other similar architectures present results limited to $30 \mathrm{kbps}$ [28].

The time responsiveness of the control network is a major requirement for purpose of synchronization and real-time control messages delivery. Therefore, network latency must be bounded up to a given threshold. The worst case latency measured to deliver a message in the network was $50 \mathrm{~ms}$ by hop ( $1 \mathrm{~ms}$ in the best case). For instance, considering a street lighting unit located 10 kilometers far away from the utility control center, node spacing from 40 to 50 meters, and average radio range around 100 meters, a message takes around 2 seconds to reach its destination $(200 \mathrm{~ms}$ in the best case and limited to $10 \mathrm{~s}$ for all transmissions with worst case delivery time). These results indicate that the proposed network is suitable to be applied for controlling a street lighting system.

Besides the related advantages to the network performance and its responsiveness, the use of a RTOS in such application also allows better energy efficiency for the control module. For instance, the microcontroller can enter into sleep mode during its idle time, thus reducing its power consumption, as shown in Figure 7. This figure shows the variation in the current consumption of the control module during the data acquisition.

In the proposed system, the control unit is responsible for controlling the LED driver, realizing data acquisition and implementing the network stack. Due to tight deadlines, the most critical tasks are the driver control and data acquisition and computation. For each cycle of the $60 \mathrm{~Hz}$ sine wave, the data of power, total harmonic distortion, power factor and accumulated energy must be calculated. To avoid data loss during this calculation, a double buffer was applied. Therefore, in the same time that calculations are performed with the data contained in a buffer, the voltage and current

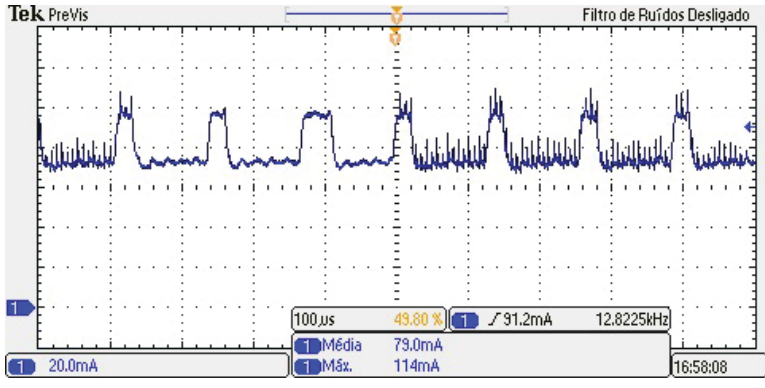

Fig. 7. Current consumption of the control module during the data acquisition $(20 \mathrm{~mA} / \mathrm{div}, 100 \mu \mathrm{s} / \mathrm{div})$.

data remain to be acquired in the other data buffer. As one can see, the time for these calculations should not exceed 16.66 $\mathrm{ms}$ (period of the $60 \mathrm{~Hz}$ wave). Such requirement is readily accomplished with the used microcontroller, as can be seen in Figure 8, where the processing of all data does not exceed 400 $\mu \mathrm{s}$.

The processing time of a received packet is higher when the LED lamp is on or when the battery is being charged, since the device performs 128 measurements of voltage and current for every $60 \mathrm{~Hz}$ cycle, as well as controls the LEDs current. The time between each acquisition is $130.2 \mu$ s, while the processing time of each acquisition is approximately 40 $\mu \mathrm{s}$ (context switches, analog to digital conversion, buffering, etc.). The acquisition of these data has a higher priority than packet processing on the network, thus increasing the average packet processing time. We also have measured a total time of $2 \mathrm{~ms}$ to process the data computation, as well as reception, routing and retransmission of a network packet. However, such latency in the packet processing is negligible, since the IEEE 802.15.4 ${ }^{\mathrm{TM}}$ constraints present much higher impact in the total time for the packet forwarding.

\section{CONCLUSION}

This paper presented a design methodology for a LED street lighting system based on a single flyback converter, as well as a possible approach for a control network intended to manage such system. The proposed converter is capable to supply the LEDs by mains or by battery and, recharge the battery when it is necessary. This is possible because the charging current of the battery bank is designed to be equal to the current of the LEDs. Thus, the battery can be recharged when connected in series with the LEDs, simplifying the feedback circuit and reducing the amount of components.

The design methodology showed that the flyback converter can also provide high power factor and low THD in the input current when supplied by mains. Thus, the advantage of a single-stage converter compared to integrated converters is the reduced number of components, and low voltage and current stress on the switch. However, the output capacitor is usually higher in order to filter the low frequency ripple present in the load. In this topology, the source of the switch is connected to the negative terminal of the battery, which allows the gate driver circuit to be powered directly by the battery without the need of auxiliary sources. The experimental results prove the effectiveness of the proposed methodology and shows that the 


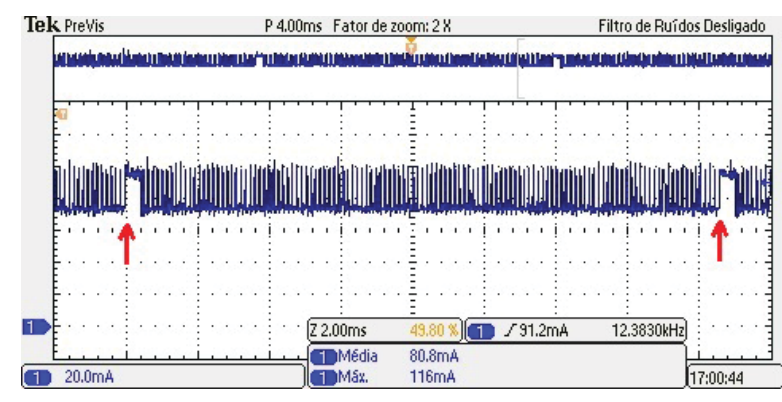

Fig. 8. Computation time of the rms voltage and current, real, reactive and apparent power, power factor, THD and accumulated energy (20 $\mathrm{mA} / \mathrm{div}, 2 \mathrm{~ms} / \mathrm{div}$ ).

circuit provides high efficiency, high power factor, and also meets the IEC 61000-3-2 C Class standard.

The integration of such converter with the proposed network makes the LED street lighting system capable of disconnect from the mains during peak load time, reducing its impact in the distributed power system automatically at overload conditions. Moreover, the network provides the system management, allowing measurement of the energy consumption in a per-lamp basis, preventive maintenance, system-wide synchronization, and so on.

In order to give communication capability to the developed street lighting units, an IEEE 802.15.4 ${ }^{\mathrm{TM}}$ compatible transceiver has been integrated to the control units. The network layers implemented in such transceiver are complemented by a network layer based on geographic forwarding, a widely recognized routing technique for large scale networks. The applied geographic routing scheme is presented in one of our previous works [27], which shows its efficiency when employed in sparse large scale scenarios. Such scenario is exactly the case of the street lighting system.

As final remark, experimental results showed that message delivery time is bounded, assuring network real-time responsiveness, and, consequently, the required synchronization. Therefore, the proposed control network was able to meet the requirements of a LED street lighting system, including the intelligent control needed on modern systems as well as disconnection from the mains during peak load times.

\section{ACKNOWLEDGEMENT}

The authors gratefully acknowledge the support of this work provided by CNPq, CEEE (CEEE-D 9945181), CAPES/DGU n249/11, as well as NEWMAX for donating the batteries that have been used in this work.

\section{REFERENCES}

[1] G. W. Denardin, R. P. Silveira, R. N. do Prado, and A. Campos. Specifications for a power management fieldbus. In Industrial Electronics Society, 2003. IECON '03. The 29th Annual Conference of the IEEE, volume 2, pages 1272 - 1277 Vol.2, nov. 2003.

[2] W. Yue, S. Changhong, Z. Xianghong, and Y. Wei. Design of new intelligent street light control system. In Control and Automation (ICCA), 2010 8th IEEE Inter. Conference on, pages 1423 -1427, jun. 2010.
[3] J. Chunguo, R. Liangchao, and G. Deying. Geographical routing for wsn of street lighting monitoring and control system. In Computer Design and Applications (ICCDA), 2010 Inter. Conference on, pages 235 -238, jun. 2010.

[4] J. Chunguo, S. Dongmei, and G. Deying. Design of streetlight monitoring and control system based on wireless sensor networks. In Industrial Electronics and Applications, 2007. ICIEA 2007. 2nd IEEE Conference on, pages $57-62$, may. 2007.

[5] R. Orletti, M. A. Co, D. S. L. Simonetti, and J. L. F. Vieira. Hid lamp electronic ballast with reduced component number. Industrial Electronics, IEEE Transactions on, 56(3):718 -725, mar. 2009.

[6] R. O. Sanchez, N. Vazquez, C. Hernandez, E. Rodriguez, S. Pinto, and M. Juarez. Electric dynamic modeling of hid lamps for electronic ballast design. Industrial Electronics, IEEE Transactions on, 57(5):1655 -1662, may. 2010.

[7] D. Gacio, M. Alonso, A. Calleja, J. Garcia, and M. RicoSecades. A universal-input single-stage high-powerfactor power supply for hb-leds based on integrated buck-flyback converter. Industrial Electronics, IEEE Transactions on, $\mathrm{PP}(99): 1-1,2010$.

[8] X. Long and J. Zhou. An intelligent driver for light emitting diode street lighting. In Automation Congress, 2008. WAC 2008. World, pages 1 -5, sep. 2008.

[9] R. A. Pinto, M. R. Cosetin, T. E. Bolzan, T. B. Marchesan, A. Campos, J. M. Alonso, M. A. Dalla Costa, and R. N. do Prado. A bidirectional buck-boost converter to supply leds from batteries during peak load time. In IECON 2011 - 37th Annual Conf. on IEEE Industrial Electronics Society, pages 2848 -2853, nov. 2011.

[10] M. A. Dalla Costa, G. H. Costa, A. S. dos Santos, L. Schuch, and J. R. Pinheiro. A high efficiency autonomous street lighting system based on solar energy and leds. In Power Electronics Conference, 2009. COBEP '09. Brazilian, pages 265 -273, oct. 2009.

[11] E. S. Jr. Mineiro, S. Daher, F. L. M. Antunes, and C. M. T. Cruz. Photovoltaic system for supply public illumination in electrical energy demand peak. In Applied Power Electronics Conference and Exposition, 2004. APEC '04. Nineteenth Annual IEEE, pages 1501 - 1506, 2004.

[12] R. A. Pinto, M. R. Cosetin, J. G. Roncalio, M. Melo, T.B. Marchesan, J. M. Alonso, M. A. Dalla Costa, and R. N. do Prado. High-power-factor street lighting system to supply leds without energy consumption during the peak load time. In IECON 2011 - 37th Annual Conf. on IEEE Industrial Electronics Society, pages 2947 -2952, nov. 2011.

[13] D. R. Nuttall, R. Shuttleworth, and G. Routledge. Design of a led street lighting system. In Power Electronics, Machines and Drives, 2008. PEMD 2008. 4th IET Conference on, pages 436-440, april 2008.

[14] NEWMAX. Product catalog, 2012.

[15] H. van der Broeck, G. Sauerlander, and M. Wendt. Power driver topologies and control schemes for leds. In Applied Power Electronics Conference, APEC 2007 - Twenty Second Annual IEEE, pages 1319-1325, mar 2007. 
[16] R. Krishnan. Meters of tomorrow [in my view]. Power and Energy Magazine, IEEE, 6(2):96 -94, mar. 2008.

[17] T. Khalifa, K. Naik, and A. Nayak. A survey of communication protocols for automatic meter reading applications. Communications Surveys Tutorials, IEEE, PP(99): 1 -15, 2010.

[18] V. C. Gungor, B. Lu, and G. P. Hancke. Opportunities and challenges of wireless sensor networks in smart grid. Industrial Electronics, IEEE Transactions on, 57(10):3557 -3564, oct. 2010.

[19] IEEE 802.15 WPAN Task Group 4g. Smart utility networks. Technical report, IEEE, 2010.

[20] B. Lu and V.C. Gungor. Online and remote motor energy monitoring and fault diagnostics using wireless sensor networks. Industrial Electronics, IEEE Transactions on, 56(11):4651 -4659, nov. 2009.

[21] K. Sohraby, D. Monoly, and T. Znati. Wireless Sensor Networks: Technology, Protocols and Applications. John Wiley and Sons, Inc, 2007.

[22] B. Karp and H. T. Kung. Gpsr: greedy perimeter stateless routing for wireless networks. In MobiCom '00: Proceedings of the 6th annual international conference on Mobile computing and networking, pages 243-254, New York, NY, USA, 2000. ACM.

[23] S. Giordano, I. Stojmenovic, and L. Blazevic. Position based routing algorithms for ad hoc networks: A taxonomy. In Ad Hoc Wireless Networking, pages 103136. Kluwer, 2001.

[24] S. Subramanian, S. Shakkottai, and P. Gupta. On optimal geographic routing in wireless networks with holes and non-uniform traffic. In INFOCOM 2007. 26th IEEE International Conference on Computer Communications. IEEE, pages 1019-1027, 6-12 2007.

[25] D. Chen and P.K. Varshney. A survey of void handling techniques for geographic routing in wireless networks. Communications Surveys Tutorials, IEEE, 9(1):50 -67, first 2007.

[26] J. N. Al-Karaki and A. E. Kamal. Routing techniques in wireless sensor networks: a survey. Wireless Communications, IEEE, 11(6):6 - 28, dec. 2004.

[27] G. W. Denardin, C. H. Barriquello, A. Campos, and R. N. do Prado. A geographic routing hybrid approach for void resolution in wireless sensor networks. Journal of Systems and Software, 84(10):1577 - 1590, 2011.

[28] M. M. Holland, R. G. Aures, and W. B. Heinzelman. Experimental investigation of radio performance in wireless sensor networks. In Wireless Mesh Networks, 2006. WiMesh 2006. 2nd IEEE Workshop on, pages 140 -150 , sep. 2006.

\section{BIOGRAPHIES}

Carlos Henrique Barriquello received the B.S., M.Sc., and Ph.D. in Electrical Engineering from Federal University of Santa Maria, Brazil, in 2007, 2009 and 2012, respectively. In 2012, he joined in the Department of Electronics and Computing of Federal University of Santa Maria as an Adjunct Professor. His research interests include embedded systems, wireless sensor/actuator networks and its applications in lighting and power systems.

Gustavo Weber Denardin was born in Santa Maria, Brazil, in 1978. He received the B.S., M.Sc. and Ph.D. degrees in Electrical Engineering from the Federal University of Santa Maria, Brazil, in 2002, 2004 and 2012, respectively. Since 2005, he has been with the Federal University of Technology - Parana (UTFPR), where he is currently an Adjunct Professor in the Electronics Department. His research interests include embedded systems, real-time operating systems, wireless sensor/actuator networks and its applications in lighting and power systems.

Rafael Adaime Pinto was born in Santa Maria, Brazil, in 1984. He received the B.S., M.Sc. and Ph.D. degrees in Electrical Engineering from the Federal University of Santa Maria, Brazil, in 2007 (with honors), 2008 and 2012, respectively. Since 2009, he has been with the Colégio Técnico Industrial de Santa Maria (CTISM/UFSM) as a Professor. His main areas of interest include: intelligent lighting, electronics ballast, DC/DC converter, and lightemitting-diode (LEDs). Rafael is SOBRAEP member since 2007.

Priscila Ertmann Bolzan was born in Porto Alegre, RS, Brasil, in 1992. She studies electrical engineering at Federal University of Santa Maria and she has been a researcher with the Electronic Ballast Research Group (GEDRE) since 2010.

Alexandre Campos received the B.Sc. degree from the Federal University of Santa Maria, Brazil, in 1981, the M.Sc. degree from the Federal University of Santa Catarina, Brazil, in 1986 and his Ph.D. degree from Concordia University, Canada, in 1994, all in electrical engineering. Since 1991, he has been with the Federal University of Santa Maria, Brazil, where he is currently an Associate Professor in the Electronics and Computing Department. His research directions include electronic ballasts, power converters, active power filters, embedded systems and signal processing.

Ricardo Nederson do Prado was born in Itapiranga, Brazil, in 1961. He received the B.Sc. degree from the Federal University of Santa Maria, Santa Maria, Brazil, in 1984, and the M.Sc. and Ph.D. degrees from the Federal University of Santa Catarina, Florianópolis, Brazil, in 1987 and 1993, respectively, all in electrical engineering. From 1987 to 1992, he was an assistant Professor in the Electronics Department, Federal University of Minas Gerais, Belo Horizonte, Brazil. Since 1993, he has been with the Federal University of Santa Maria, Brazil, where he is currently an Associate Professor in the Electrical Energy Processing Department. In 1997, he founded the Electronic Ballast Research Group (GEDRE). From 2005 to 2006, he was with the Fraunhofer Institute, Sankt Augustin, Germany, as a Postdoctoral Research Scholar. His research directions include high-frequency high-density power converters, fluorescent and high-pressure lamps, dimming systems, luminous efficiency, electronic ballasts, LED as a light source and power-factor correction. 